\title{
A FORMAL-LOGICAL APPROACH TO THE CONCEPT OF GOD ${ }^{1}$
}

\author{
RICARDO SOUSA SILVESTRE \\ https:/ / orcid.org/0000-0002-0635-7399 \\ Federal University of Campina Grande \\ Department of Philosophy \\ Campina Grande, P. B. \\ Brazil \\ ricardoss@ufcg.edu.br
}

\section{Article info \\ CDD: 200.1}

Received: 24.06.2021; Accepted: 28.08.2021

https://doi.org/10.1590/0100-6045.2021.V44N4.RS

\section{Keywords}

Concept of God

Formal Philosophy of Religion

Simplest Quantified Modal Logic

Religious Plurality

\begin{abstract}
In this paper I try to answer four basic questions: (1) How the concept of God is to be represented? (2) Are there any logical principles governing it? (3) If so, what kind of logic lies behind them? (4) Can there be a logic of the concept of God? I address them by presenting a formal-logical account to the concept of God. I take it as a methodological desideratum that this should be done within the simplest existing logical formalism. I start with first-order logic (FOL) with identity, and then show that its simplest modal extension (SQML, or the simplest quantified modal logic) is enough for us to formalize a minimally satisfactory theory
\end{abstract}

\footnotetext{
1 This paper is part of the project "The Rationality of Theistic Belief and the Plausibility of the Concept of God", sponsored by the John Templeton Foundation under its umbrella project "Supporting Constructive Research on the Existence of God in Portuguese-Speaking Latin America”.
} 
of the concept of God. I focus exclusively on the monotheistic concept of God.

\section{Introduction}

The analysis of the concept of God centers around divine attributes such as omniscience, omnipotence, wholly goodness, eternity, simplicity and incorporeality. Although there have been attempts to present the concept of God in such a way that these properties follow from a general definition—such as Anselm's definition of God as that than which nothing greater can be thought—or from a sole property — such as Richard Swinburne's (2016, p. 173) attempt to derive all properties from the property of omnipotence-, the concept of God is mostly characterized through a list of attributes that GOD (the entity that falls under the concept of $\mathrm{God}^{2}$ ) is supposed to possess. The attributes one chooses and the way one interprets them give rise to different views on GOD (such as classical theism, open theism, process theism and deism) and different concepts of God.

This attribute-based approach has turned the analysis of the concept of God partially into a logical inquiry (Krajewski; Silvestre 2019). Given a specific attribute-based account of God, one must deal with the issue of whether or not the

\footnotetext{
${ }^{2}$ In order to distinguish between the concept of God and the eventual object that falls under it, I will refer to the latter using capital letters. Thus, while "God" means the concept of God, "GOD" means the entity which supposedly falls under the concept of God (although most of the time I will use the complex expression "concept of God").
} 
concept at hand is consistent ${ }^{3}$. This is in fact the most basic criterion to assess the rationality of theistic belief. If God is an inconsistent concept, then belief in GOD is aprioristically irrational. This is what is at stake in the famous paradox of the stone. Can GOD create a stone so heavy that it cannot lift? If we say yes, then there is something GOD cannot do, namely to create such a stone; if we say no, then there is also something it cannot do, namely to lift the stone. In either case GOD is not omnipotent. Since this reasoning can be applied to any object whatsoever, the conclusion is that there cannot be an object that possess the property of omnipotence. Consequently, there cannot be an object that falls under the concept of God (supposing that omnipotence is one of God's divine attributes).

This is of course not new. Christian theologians have for centuries struggled with the logical problem of trinity, which is basically the problem of dealing with the (apparent) inconsistency of orthodox Christian concept of God. From the philosophical side, Anselm for example has wondered about the individual and conjoint consistency of the attributes he derived from his definition of God ${ }^{4}$. Leibniz

3 Although the term "inconsistent" is usually applied to sets of propositions, it can easily be extended so as to apply also to concepts. See (Krajewski; Silvestre 2019, pp. 1001-1002). For example, defining it in terms of impossibility, we would have as follows: a concept $c$ is inconsistent iff it is logically impossible that there is an entity that falls under $c$.

${ }^{4} \mathrm{He}$ writes, for instance, as follows: "Now, since to be able to perceive and to be omnipotent, merciful, and impassible is better than not to be [any of these], how are You able to perceive if You are not something corporeal, or how are You omnipotent if You cannot do all things, or how are You both merciful and impassible?" (Foltz 2019, p. 272) How God can be omnipotent if he cannot do all things? And how can he be both merciful and 
went further and pondered about the compossibility of all divine attributes. Attempting to fill what he took to be a shortcoming in Descartes' ontological argument, he endeavored to show that all divine attributes can coexist together in a single entity. What seems genuinely new is taking the debate into the formal arena and providing a formal-logical approach to the concept of God.

There have been attempts to account for the consistency of God from a formal point of view ${ }^{5}$. But a formal-logical approach to God should go beyond mere consistency issues. Sure, the question of whether God is consistent is a very important one. But there are other, more fundamental questions about the concept of God that seem not to have been properly addressed. (1) How the concept of God is to be represented? (2) Are there any logical principles governing it? (3) If so, what kind of logic lies behind them? (4) Can there be a logic of the concept of God after all?

To see that these questions matter, notice that any analysis of the concept of God requires that we provide a representation for it. The conclusions we make about the concept of God-that it is consistent or that there is an object that falls under it, for example-will someway or other be affected by the way we represent God and the framework within which the representation occurs. Such a

impassible at the same time? For if he is impassible, he has no compassion. And if he has no compassion, Anselm says, he does not have a heart sorrowful out of compassion for the wretchedwhich means he lacks attribute of being merciful.

${ }^{5}$ A crucial part of Gödel's (1995) ontological argument is to show that GOD is possible; it therefore can be seen also as an attempt to show that the concept of God is consistent. There have been many attempts to formally deal with the logical problem of trinity; see for example (Molto 2017) and (Branson 2019). For the paradox of the stone see (Hernández-Ortiz; Cantero-Flores 2019).

Manuscrito - Rev. Int. Fil. Campinas, v. 44, n. 4, pp. 224-260, Oct.-Dec. 2021. 
dependence will of course be much more explicit in the case the analysis is a formal one.

To see that the questions are not trivial, notice that something that permeates much of the discourse about God in metaphysical philosophy of religion is the idea that there is a unique concept of God. The very use of the expression "the concept of God" presupposes that, as do the questions (1)-(4) above. But this seems to conflict with the pragmatics or social dimension, so to speak, of the concept of God.

Every monotheistic religious tradition-and sometimes every school within traditions - seems to have its own concept of God. According to orthodox Christianity, GOD is a trinitarian entity ${ }^{6}$. Islam, on the other hand, emphasizes that GOD is strictly singular (tawhīid), unique (wāhid) and inherently One (ahad) (Esposito 1998, p. 88). In its turn, the so-called "Hindu bible", the Bhagavad-gitan, while stating that GOD (who is identified with the speaker of the text, Krṣna) is one ${ }^{7}$, claims that He is identical with everything (Resnick 1995, p. 7-9;13-17). There is plurality even within traditions. For example, when dealing with the problem of the Trinity, Christian scholars have proposed different and conflicting concepts of God (Tuggy 2016). From a philosophical viewpoint, there seems to be a plurality of concepts of God

\footnotetext{
6 This appears very clearly, for example, in the Athanasian Creed. Out of its 44 theses, three of them state as follows: (1) "We worship GOD in Trinity and Trinity in Unity... Neither confounding the persons nor dividing the substance."; (2) "So the Father is GOD, the Son is GOD, and the Holy Spirit is GOD."; (3) "And yet they are not three GODS, but one GOD."

${ }^{7} \mathrm{He}$ is the great Lord of all the worlds (5.29), the Supreme Divine Person (10.12), the God of the gods (10.14) and their origin (10.12, 11.38); no one is equal to or greater than Him (11.38). See (Resnick 1995).
} 
too. Philosophers have proposed different accounts of God, ending up with different concepts of God. From the standpoint of divine attributes, there is a multitude of concepts of God that can be obtained from different subsets of attributes.

Despite of this, I do believe that there are reasonable answers to questions (1)-(4). In special, I believe that there is a positive answer to (4). To show why I do believe so, I shall introduce what I might call a formal-logical account to the concept of God. I take it as a methodological desideratum that a formal-logical account of God should be done within the simplest existing logical formalism. The reason behind this is that only if existing logical systems are unable to satisfactorily deal with these issues should we introduce a new formalism specifically aimed at this. As a secondary goal, thus, I will show that there is no need to develop a new logic to deal with the concept of God.

I start with first-order logic (FOL) with identity, and then show that its simplest modal extension (SQML, or the simplest quantified modal logic) is enough for us to formalize a minimally satisfactory theory of the concept of God. I still work within an attribute-based approach. Furthermore, I focus exclusively on the monotheistic concept of God. When I write "concept of God" (or simply "God") I really mean the monotheistic concept of God. The reason for that is very simple. This is the kind of concept that is at the center of the philosophical debate on the rationality of theism. When contemporary philosophers argue for and against the existence of God, or for and against the consistency of the concept of God, they generally assume a monotheistic approach. 


\section{Representing the Concept of God}

Concepts are often thought of as abstract objects (Margolis; Laurence 2007). Although as an ontological claim that is certainly controversial, as a representational claim it does not seem to be that problematic. Concepts can indeed be represented as abstract objects (Zalta 2000). If we take this idea seriously, then first-order logic (FOL) will naturally be our first choice as a logical representational framework.

Abstract objects are usually seen in contradistinction with concrete objects, so that abstractedness ends up being the same as non-concreteness. A simpler view is what David Lewis (1986, p. 83) calls the negative path. According to this view, abstract objects are objects that are causally ineffective. (Since concrete objects by definition have spatiotemporal location, they are necessarily causal effective.) A consequence of this is that nonabstractedness and concreteness are not anymore equivalent. Concreteness is now a proper subcategory of nonabstractness: there might be nonabstract non-concrete objects, that is, causally effective objects without spaciotemporal location ${ }^{8}$. This is of

${ }^{8}$ Commenting on this view of abstract objects, Gideon Rosen (2020) writes as follows: "It is widely maintained that causation, strictly speaking, is a relation among events or states of affairs. If we say that the rock-an object-caused the window to break, what we mean is that some event or state (or fact or condition) involving the rock caused the break. If the rock itself is a cause, it is a cause in some derivative sense. But this derivative sense has proved elusive. The rock's hitting the window is an event in which the rock 'participates' in a certain way, and it is because the rock participates in events in this way that we credit the rock itself with causal efficacy. But what is it for an object to participate in an event? Suppose John is thinking about the Pythagorean Theorem and you ask him to say what's on his mind. His response is an 
course needed if we want to cope with the idea that GOD, although non-concrete, can interact causally with the world.

From the point of view of FOL language, abstract objects can be represented in the same way as nonabstract objects: through variables and constants. The semantical counterpart of this is that our domain $\mathrm{D}$ will be composed by two sets, one containing abstract objects and other containing nonabstract objects. Among abstract objects, some may be concepts. Let $\mathrm{C}$ and $\mathrm{A}$ be two special predicate symbols representing, respectively, the property of being a concept and the property of abstractedness; $\mathrm{C}(\mathrm{x})$ thus means that $x$ is a concept and $\mathrm{A}(\mathrm{x})$ that $x$ is abstract.

$$
\text { (C1) } \forall \mathrm{x}(\mathrm{C}(\mathrm{x}) \rightarrow \mathrm{A}(\mathrm{x}))
$$

is thus true.

Additional special predicate symbols are still to be introduced. A formula $\alpha$ is said to be SP-free iff it does not

event-the utterance of a sentence; and one of its causes is the event of John's thinking about the theorem. Does the Pythagorean Theorem 'participate' in this event? There is surely some sense in which it does. The event consists in John's coming to stand in a certain relation to the theorem, just as the rock's hitting the window consists in the rock's coming to stand in a certain relation to the glass. But we do not credit the Pythagorean Theorem with causal efficacy simply because it participates in this sense in an event which is a cause. The challenge is therefore to characterize the distinctive manner of 'participation in the causal order' that distinguishes the concrete entities. This problem has received relatively little attention. There is no reason to believe that it cannot be solved. But in the absence of a solution, this standard version of the Way of Negation must be reckoned a work in progress." 
contain any special predicate symbols. A set of formulas $\Gamma$ is $S P$-free iff it contains only SP-free formulas.

The concept of God is represented by special constant $g$, which denotes this distinguished abstract object that I take to be the concept of God. The following formula is thus true:

\section{(C2) $\mathrm{C}(\mathrm{g})$}

Notice that this approach presupposes the idea mentioned earlier that there is a unique concept of God. Let us call this the singularity assumption:

(SA) There is a unique concept of God.

From a formal viewpoint, SA is guaranteed by standard Tarskian FOL semantics. Since the semantic connection between constants and objects of $\mathrm{D}$ is made by a function, there is at most one object of D that is the reference of $g$.

As I have mentioned, SA seems to conflict with the pragmatics or social dimension of the concept of God. Every monotheistic religious tradition-and sometimes every school within traditions - seems to have its own concept of God. Thus, the claim below seems to be true:

(PG)There is a plurality of concepts of God.

Trivially enough, PG contradicts SA.

This can be sorted out in a straightforward manner. In FOL an object is represented or described with the help of predicate symbols. Naturally there can be more than one description of the same object. By offering multiple descriptions of $g$ we can thus account for PG at the same time that retain SA.

Let the predicate symbols $\mathrm{P}, \mathrm{K}, \mathrm{B}$ and $\mathrm{C}$ be such that $\mathrm{P}(\mathrm{x})$ means that $x$ is omnipotent, $\mathrm{K}(\mathrm{x})$ that $x$ is omniscient, $\mathrm{B}(\mathrm{x})$ 
that $x$ is wholly good and $\mathrm{R}(\mathrm{x})$ that $x$ is the creator and sustainer of the world. The formula below represents what we might call the triple-O view of GOD:

$$
\left(\mathrm{P}_{1}\right) \mathrm{P}(\mathrm{g}) \wedge \mathrm{K}(\mathrm{g}) \wedge \mathrm{B}(\mathrm{g}) \wedge \mathrm{R}(\mathrm{g})
$$

From it, other views can be obtained. If $3 \mathrm{O}(\mathrm{x})$ is an abbreviation for $\mathrm{P}(\mathrm{x}) \wedge \mathrm{K}(\mathrm{x}) \wedge \mathrm{B}(\mathrm{x}) \wedge \mathrm{R}(\mathrm{x})$ and $\mathrm{F}, \mathrm{T}, \mathrm{S}$ and $\mathrm{E}$ are such that $\mathrm{F}(\mathrm{x})$ means that $x$ incarnates in the world, $\mathrm{T}(\mathrm{x})$ that $x$ is transcendental to the world, in the sense of being outside space and time, $\mathrm{S}(\mathrm{x})$ that $x$ respects the free-will of its creatures to the extent of allowing that they do not worship it, and $\mathrm{E}(\mathrm{x})$ that $x$ demands exclusive worship for itself, we might have the following alternative views:

$$
\begin{aligned}
& \left(\mathrm{P}_{2}\right) 3 \mathrm{O}(\mathrm{g}) \wedge \mathrm{F}(\mathrm{g}) \\
& \left(\mathrm{P}_{3}\right) 3 \mathrm{O}(\mathrm{g}) \wedge \mathrm{T}(\mathrm{g}) \\
& \left(\mathrm{P}_{4}\right) 3 \mathrm{O}(\mathrm{g}) \wedge \mathrm{S}(\mathrm{g}) \\
& \left(\mathrm{P}_{5}\right) 3 \mathrm{O}(\mathrm{g}) \wedge \mathrm{E}(\mathrm{g})
\end{aligned}
$$

I call formulas $\mathrm{P}_{1}, \mathrm{P}_{2}, \mathrm{P}_{3}, \mathrm{P}_{4}$ and $\mathrm{P}_{5}$ descriptive concepts of God, or D-concepts of God for short. They might be seen as different attempts to characterize the one and same concept of God. Thus, while there is only one concept of God (SA), which is the object referred to by $g$, there might be several D-concepts of God (PG).

From the point of view of the logical language, a Dconcept of God is a positive description of $g$ containing predicates that can be possessed by nonabstract objects. It can thus be of any logical form, provided it does not contain either $\mathrm{C}$ or $\mathrm{A}$ and entails a positive atomic formula about $g$. The positiveness requirement is important, for an exclusively negative description does not really characterize what God is, only what it is not. Formally we have as follows. Let $\delta$ be 
a SP-free FOL formula9. $\delta$ is a D-concept of God iff $\delta \vdash \mathrm{D}(\mathrm{g})$, where $\mathrm{D}$ is an arbitrary predicate symbol and $\vdash$ is FOL (with identity) deductive relation, defined in any of the usual ways.

There are of course logical relations between different Dconcepts of God. Let a theological background $\Gamma$ be a SP-free set of FOL formulas representing known facts about the world as well as formulas setting the relations between the pertinent (non-special) predicate symbols. In addition, let $\delta$ and $\delta$ ' be two D-concepts of God. $\delta$ and $\delta$ ' are mutually $\Gamma$ contradictory iff $\Gamma \cup\left\{\delta, \delta^{\prime}\right\}$ is inconsistent. $\delta$ is $\Gamma$ contradictory iff $\Gamma \cup\{\delta\}$ is inconsistent. $\delta \Gamma$-includes $\delta$ ' iff $\Gamma \cup\{\delta\} \vdash \delta \mathrm{X}^{\prime}, \mathrm{P}_{3}, \mathrm{P}_{4}$ and $\mathrm{P}_{5}$ all include $\mathrm{P}_{1}$. Suppose $\Gamma$ is such that $\Gamma \vdash \mathrm{P}_{6} \wedge \mathrm{P}_{7}$, where $\mathrm{P}_{6}$ and $\mathrm{P}_{7}$ are as follows:

$$
\begin{aligned}
& \left(\mathrm{P}_{6}\right) \forall \mathrm{x}(\mathrm{S}(\mathrm{x}) \rightarrow \neg \mathrm{E}(\mathrm{x})) \\
& \left(\mathrm{P}_{7}\right) \forall \mathrm{x}(\mathrm{T}(\mathrm{x}) \rightarrow \neg \mathrm{F}(\mathrm{x}))
\end{aligned}
$$

$\mathrm{P}_{2}$ and $\mathrm{P}_{3}$, as well as $\mathrm{P}_{4}$ and $\mathrm{P}_{5}$ are then mutually $\Gamma$ contradictory. Supposing in addition that $\Gamma$ is such that $\Gamma \vdash$ $\mathrm{P}_{8}$, where $\mathrm{P}_{8}$ is as follows:

$$
\left(\mathrm{P}_{8}\right) \forall \mathrm{x}(\mathrm{B}(\mathrm{x}) \rightarrow \mathrm{S}(\mathrm{x}))
$$

, then $\mathrm{P}_{5}$ is a $\Gamma$-contradictory D-concept of God.

9 A FOL formula is a formula belonging to the language of FOL. Similarly, a SQML formula is a formula belonging to the language of SQML. 


\section{Instantiation and the Monotheistic Concept of God}

Concepts can be instantiated. Given concept $c$, there might be an object $o$ that falls under $c$, in this case we say that $o$ is an instance of $c$. Since I am representing concepts as abstract objects (that possess properties), instantiation must be seen in terms of similarity: an object $o$ is an instance of concept $c$ if $o$ is similar (enough) to $c^{10}$. This similarity relation can be represented with the help of the special (binary) predicate symbol $\cong x \cong y$ means that $x$ is similar to $y^{11}$. $\cong$ might be formalized with the help of the following formulas, which set $\cong$ as an equivalence relation:

$$
\begin{aligned}
& \text { (M1) } \forall \mathrm{x}(\mathrm{x} \cong \mathrm{x}) \\
& \text { (M2) } \forall \mathrm{x} \forall \mathrm{y}(\mathrm{x} \cong \mathrm{y} \rightarrow \mathrm{y} \cong \mathrm{x}) \\
& \text { (M3) } \forall \mathrm{x} \forall \mathrm{y} \forall \mathrm{z}(\mathrm{x} \cong \mathrm{y} \rightarrow(\mathrm{y} \cong \mathrm{z} \rightarrow \mathrm{x} \cong \mathrm{z}))
\end{aligned}
$$

Additionally, we have the following schemas of formulas:

(M4) $\forall x \forall y(x \simeq y \rightarrow(\alpha \leftrightarrow \alpha[y / x]))$, where $\alpha$ is a SPfree formula

(M5) $\forall \mathrm{x}((\alpha \leftrightarrow \alpha[\mathrm{g} / \mathrm{x}]) \rightarrow \mathrm{x} \cong \mathrm{g})$, where $\alpha$ is a Dconcept of God

10 As far as instantiation is concerned, this is the general approach followed by theories of concepts such as prototype theory and exemplar theory. See (Laurence; Margolis 1999) and (Murphy 2002).

$11 \cong$ is not a logical symbol, but an ordinary binary predicate symbol being used in a relational form (rather than in the standard form, which would be something like this: $\cong(x, y))$. 
$\alpha[y / x]$ is the result of substituting $x$ for some, but not necessarily all, occurrences of $y$ in $\alpha$. Given a specific Dconcept of God $\delta, \forall \mathrm{x}((\delta \leftrightarrow \delta[\mathrm{g} / \mathrm{x}]) \rightarrow \mathrm{x} \cong \mathrm{g})$ is called a $\delta$ instance of $M 5$.

Here I am interpreting $\cong$ in the strongest possible way, in terms of an identity-like relation ${ }^{12}$. M4 is a general similarityconceptual version of the law of indiscernible of identicals. In its turn, M5 is a similarity-conceptual version of the law of identity of indiscernibles restricted to God. M5 is the basis of our categorization process; it allows us to say whether a nonabstract object is an instance of the concept of God.

I say M5 is a restricted version of the law of identity of indiscernible because it only works if $\delta$ is a purportedly, complete D-concept of God, so to speak. If we set, for example, $\mathrm{P}_{1}$ as a $\mathrm{D}$-concept of God, then if a nonabstract object $a$ is such that $\mathrm{P}(\mathrm{a}) \wedge \mathrm{K}(\mathrm{a}) \wedge \mathrm{B}(\mathrm{a}) \wedge \mathrm{R}(\mathrm{a})$, then $\mathrm{a} \cong g$. But according to my definition, $\mathrm{P}(\mathrm{g}) \wedge \mathrm{K}(\mathrm{g})$ is also a D-concept of God. If, therefore, another nonabstract object $b$ is such that $\mathrm{P}(\mathrm{b}) \wedge \mathrm{K}(\mathrm{b})$ and $\neg \mathrm{B}(\mathrm{b}) \wedge \neg \mathrm{R}(\mathrm{b})$, through M5 we will have the unwanted conclusion that $\mathrm{b} \cong \mathrm{g}$. M5 should therefore be applied only to those formulas we set as D-concepts of God. I show below how this can be done ${ }^{13}$.

Instantiation is made clear with the help of I, our last special predicate symbol:

$$
\text { (C3) } \forall \mathrm{x} \forall \mathrm{y}(\mathrm{I}(\mathrm{x}, \mathrm{y}) \leftrightarrow(\mathrm{x} \cong \mathrm{y}) \wedge \neg \mathrm{C}(\mathrm{x}) \wedge \mathrm{C}(\mathrm{y}))
$$

$12 \mathrm{~A}$ weaker interpretation of $\cong$ would require a richer formalism than FOL.

13 Or course, if we were using second order logic, the representation of (M5) would be much simpler. 
$\mathrm{I}(\mathrm{x}, \mathrm{y})$ means that $x$ is an instance of concept $y$. See that C3 allows for abstract instances of concepts ${ }^{14}$. But we know that if GOD exists, it is a nonabstract entity. Therefore, we need a postulate requiring that for $x$ to be an instance of $g$, it must be nonabstract:

$$
\text { (C4) } \forall \mathrm{x}(\mathrm{I}(\mathrm{x}, \mathrm{g}) \rightarrow \neg \mathrm{A}(\mathrm{x}))
$$

C3 also allows a concept to have more than one instance. This of course is a problem. Since I am dealing with the monotheistic concept of God, I am presupposing what might be termed the assumption of monotheism:

$$
\begin{aligned}
& \text { (AM) There is at most one entity that falls under the } \\
& \text { concept of God. }
\end{aligned}
$$

A stronger, extensional version of (AM) can be stated as follows:

(EAM) There is at most one GOD; otherwise said, the number of extensions of the word "GOD" is at most one ${ }^{15}$.

We therefore need an additional postulate to guarantee that our concept of God $g$ is in fact monotheistic:

$$
\text { (C5) } \forall \mathrm{x} \forall \mathrm{y}(\mathrm{I}(\mathrm{x}, \mathrm{g}) \rightarrow(\mathrm{I}(\mathrm{y}, \mathrm{g}) \rightarrow \mathrm{x}=\mathrm{y}))
$$

\footnotetext{
14 Although an abstract object, the number 2 is an instance of the concept of number.

15 Although (EAM) entails (AM), the converse is not true.
} 
C5 says that if $x$ and $y$ are both instances of $g$, then $x$ is identical to $y$ (or to be more precise, $x$ and $y$ refer to the same object).

Now I can present the first version of what I call a theory of the concept of God. I use the word "theory" more in the technical-logical sense of a set of formulas represented within a specific logical system than in the philosophical sense, although this philosophical sense is undoubtedly there. Let $\Gamma$ be a theological background. Let also $\Lambda$ be a SPfree set of FOL formulas containing only D-concepts of God. The $\Lambda$-FOL theory of the concept of God applied to $\Gamma$ is the set of FOL formulas $\Gamma_{\Lambda}$ composed by (and only by) $\Gamma$ and $\Lambda$ $\left(\Gamma \cup \Lambda \subset \Gamma_{\Lambda}\right)$, C1-C5, M1-M3, all instances of M4 and all $\delta$ instances of M5, for all $\delta \in \Lambda$.

Here the idea is that the formulas of $\Lambda$, and only the formulas of $\Lambda$, be taken as D-concepts of God, so that M5 applies only to them. If $\Gamma$ is as described above and $\Lambda$ is $\left\{\mathrm{P}_{1}, \mathrm{P}_{2}, \mathrm{P}_{4}\right\}$, for example, then only the three $\delta$-instances of M5 below belong to $\Gamma_{\Lambda}$ :

$$
\begin{aligned}
& \left(\mathrm{P}_{9}\right) \forall \mathrm{x}((3 \mathrm{O}(\mathrm{g}) \leftrightarrow 3 \mathrm{O}(\mathrm{x})) \rightarrow \mathrm{x} \cong \mathrm{g}) \\
& \left(\mathrm{P}_{10}\right) \forall \mathrm{x}((3 \mathrm{O}(\mathrm{g}) \wedge \mathrm{F}(\mathrm{g}) \leftrightarrow 3 \mathrm{O}(\mathrm{x}) \wedge \mathrm{F}(\mathrm{x})) \rightarrow \mathrm{x} \cong \mathrm{g}) \\
& \left(\mathrm{P}_{11}\right) \forall \mathrm{x}((3 \mathrm{O}(\mathrm{g}) \wedge \mathrm{S}(\mathrm{g}) \leftrightarrow 3 \mathrm{O}(\mathrm{x}) \wedge \mathrm{S}(\mathrm{x})) \rightarrow \mathrm{x} \cong \mathrm{g})
\end{aligned}
$$

$\Lambda$ cannot however be such that $\left\{\mathrm{P}_{2}, \mathrm{P}_{3}\right\} \subseteq \Lambda$. Since $\mathrm{P}_{2}$ and $\mathrm{P}_{3}$ are mutually $\Gamma$-contradictory, $\Gamma_{\Lambda}$ would be trivial in this case. But this is a problem. As we have seen, our social reality might contain contradictory concepts of God. Therefore, as promising as it may be, this FOL approach to the concept of God is not comprehensive enough to deal with PG.

This is however not the only reason why this FOL approach to the concept of God is unable to properly deal with PG. Although it in one sense deals with several 
consistent concepts of God, in a deeper sense even this plurality is not contemplated, for $\Lambda$ (and any set of FOL formulas whatsoever) contain at most one $\mathrm{D}$-concept of God.

In standard Tarskian semantics, $\Lambda$ corresponds to a specific set of FOL models or interpretations, namely, those models that satisfy all formulas of $\Lambda^{16}$. Let us call this set of models $\mathscr{M}_{\Lambda}$. A model $\mathrm{M} \in \mathscr{M}_{\Lambda}$ offers us a complete description of all objects, in the sense of all properties, be them relational or not, that they possess; in one sense, it is a complete description of the part of reality that can be expressed with the help of our logical language. Since our logical language contains constant $g$, $\mathrm{M}$ offers us a complete description of the abstract object referred to by $g$, providing thus a complete description of the concept of God: it is a complete theological worldview, as we might call it. M thus presents us with one and at most one D-concept of God. But that is not yet the D-concept of God contained in $\Lambda$. $\Lambda$ 's D-concept of God is what results from the intersection of all models $\mathrm{M} \in \mathscr{M}_{\Delta}$ regarding $g$, which is still a unique D-concept.

Because of that, we are not able, in this FOL approach, to account for PG. From a semantical standpoint, we cannot represent inside the same model this essential aspect of our social reality, namely that there is a plurality of concepts of

16 I am using the terms "interpretation" and "model" interchangeably as meaning the semantic structure responsible for attributing meaning to the basic components of the logical language (constants, predicate, function symbols, etc.) and, as a consequence of that, responsible for attributing truth-value to the formulas of the language. When the truth-value is "true" for a formula $\alpha$ we say that $\alpha$ is valid in the model. It should be noted that many authors use the term "model" in a different way, to refer to those first order interpretations (or models, according to my terminology) which satisfy a formula or a set of formulas. 
God. One might reply that two models M and M' describe two different D-concepts and therefore allow for the representation of a plurality of concepts of God. But this is not completely accurate. As we have seen, all D-concepts of God are attempts to characterize the one and the same abstract object. But there is no guarantee that $\mathrm{M}$ and $\mathrm{M}^{\prime}$ assign to the constant $g$ the same object. If they indeed assign $g$ to different objects, then they cannot strictly speaking be considered D-concepts of God (which are attempts to characterize the same concept, namely g).

\section{The Simplest Quantified Modal Logic (SQML)}

One way to solve these issues is to use a modal, possible world framework with rigid designators and constant domain K-semantics. In the solution I am proposing here, constants denote the same object in all possible worlds (rigid designators), the objects of $\mathrm{D}$ exist in all possible worlds (constant domain) and the set of possible worlds $\mathrm{W}$ is not the same as the set of all logically possible worlds (Ksemantics) ${ }^{17}$. It corresponds to what many people call the simplest quantified modal logic (SQML) ${ }^{18}$.

Following the standard modal logic semantic notation, a frame $\mathrm{F}$ is a pair $<\mathrm{W}, \mathrm{R}>$ where $\mathrm{W}$ is a set of possible worlds and $\mathrm{R}$ an accessibility relation between worlds. In SQML, a model is a quadruple $\langle\mathrm{W}, \mathrm{R}, \mathrm{D}, \mathrm{V}\rangle$, where $\langle\mathrm{W}, \mathrm{R}\rangle$ is a frame $\mathrm{F}$. We say that $\mathrm{M}$ is based on $\mathrm{F}$. If $\mathrm{F}$ belongs to a specific

\footnotetext{
${ }^{17}$ See (Schurz 2002).

${ }^{18}$ From the point of view of the logical language, SQML requires us to extend FOL language so that the necessity modal operator $\square$ is added: if $\alpha$ is a formula, then $\square \alpha$ is also a formula. The possibility operator $\diamond$ is defined as usual: $\diamond \alpha={ }_{\text {def }} \neg \square \neg \alpha$.
} 
class of frames $\mathscr{H}$, we say that $\mathrm{M}$ is an $\mathscr{H}$-model. $\mathrm{D}$ is a nonempty domain of objects to be used in connection with all worlds (it is a constant domain) and $\mathrm{V}$ is a pair of valuation functions $\left\langle V_{C}, V_{P}>\right.$ such that $V_{C}$ maps each constant symbol to an object of the domain $\mathrm{D}$, and $\mathrm{V}_{\mathrm{P}}$ maps each $n$-ary predicate symbol and world $w \in W$ to a n-tuple drawn from D. While the extension of constants is the same for all worlds - they are rigid designators-, the extension of predicates changes from world to world.

Unlike some formulations of SQML (Linsky; Zalta 1994) (Menzel 2018), my model M does not contain a distinguished member of $\mathrm{W}$ meant to represent the actual world. The philosophical reasons for that will become clear in the next section ${ }^{19}$.

An assignment in $\mathrm{M}$ is a function $s$ that assigns each variable symbol to an object of D. s[x $\mid \mathrm{o}]$ is the assignment that is exactly like $s$, except for variable $x$, which is assigned to $\mathrm{o} \in \mathrm{D}$. Given a model $\mathrm{M}=\langle\mathrm{W}, \mathrm{R}, \mathrm{D}, \mathrm{V}\rangle$ and an assignment $s$ in $\mathrm{M}$, the denotation (or extension) function $\mathrm{d}_{\mathrm{M}, \mathrm{s}}(\mathrm{x})$ is defined as follows: if $x$ is a constant symbol then $\mathrm{d}_{\mathrm{M}, \mathrm{s}}(\mathrm{x})=\mathrm{V}_{\mathrm{C}}(\mathrm{x})$; if $x$ is a variable then $\mathrm{d}_{\mathrm{M}, \mathrm{s}}(\mathrm{x})=\mathrm{s}(\mathrm{x})$.

Let $\mathrm{M}$ be a model $<\mathrm{W}, \mathrm{R}, \mathrm{D}, \mathrm{V}\rangle$, w $\in \mathrm{W}$ a world of $\mathrm{W}, s$ an assignment in $\mathrm{M}, \alpha$ and $\beta$ formulas, $p$ an $n$-ary predicate symbol, $x$ a variable symbol, $t$ and $t$ two terms, and $t_{1}, \ldots, t_{n}$ a $n$-tuple of terms. The validity relation $\Vdash$, having as parameters $\mathrm{M}, w$ and $s$ on one hand, and a formula $\varphi$ on the other $\left(\mathrm{M} \Vdash_{\mathrm{w}, \mathrm{s}} \varphi\right.$ means that $\varphi$ is valid in $\mathrm{M}$ and $w$ given $\left.s\right)$ is defined as follows:

\footnotetext{
${ }^{19}$ I might argue that having a meeker model structure where there is no such distinguished world strengths the term "simplest" in the expression "simplest quantified modal logic".
} 
- $\mathrm{M} \quad \mathbb{F}_{\mathrm{w}, \mathrm{s}} \mathrm{p}\left(\mathrm{t}_{1}, \ldots, \mathrm{t}_{\mathrm{n}}\right)$ iff $\quad<\mathrm{d}_{\mathrm{M}, \mathrm{s}}\left(\mathrm{t}_{1}\right), \quad \ldots$, $\mathrm{d}_{\mathrm{M}, \mathrm{s}}\left(\mathrm{t}_{1}\right)>\in \mathrm{V}_{\mathrm{P}}(\mathrm{p}, \mathrm{w})$;

- $\quad M \Vdash_{w, s} \mathrm{t}^{\prime}=\mathrm{t}^{\prime \prime}$ iff $\mathrm{d}_{\mathrm{M}, \mathrm{s}}\left(\mathrm{t}^{\prime}\right)=\mathrm{d}_{\mathrm{M}, \mathrm{s}}\left(\mathrm{t}^{\prime \prime}\right)$;

- $\quad \mathrm{M} \Vdash_{\mathrm{w}, \mathrm{s}} \neg \alpha$ iff $\mathrm{M}{ }_{\mathrm{w}, \mathrm{s}} \neg \alpha$;

- $M \Vdash_{w, s} \alpha \wedge \beta$ iff $M \Vdash_{w, s} \alpha$ and $M \Vdash_{w, s} \beta$;

- $\quad M \Vdash_{w, s} \alpha \vee \beta$ iff $M \Vdash_{w, s} \alpha$ or $M \Vdash_{w, s} \beta$;

- $\quad M \Vdash_{w, s} \alpha \rightarrow \beta$ iff $M H_{w, s} \alpha$ or $M \Vdash_{w, s} \beta$;

- $\quad M \Vdash_{w, s} \forall x \alpha$ iff for any $o \in D, M \Vdash^{w, s[x \mid o]}, \alpha$;

- $\quad M \Vdash_{w, s} \square \alpha$ iff for any $w^{\prime} \in W$ such that wRw', M $\Vdash_{w^{\prime}, s} \alpha$.

Let $\varphi$ be a formula and M a model. Two more general validity relations are defined as follows $\left(M \Vdash_{w} \varphi\right.$ means that $\varphi$ is valid in $\mathrm{M}$ and $w$; $\mathrm{M} \Vdash \varphi$ that $\varphi$ is valid in $\mathrm{M}$ ):

- $\quad \mathrm{M} \Vdash_{\mathrm{w}} \varphi$ iff for any assignment $s$ in $\mathrm{M}, \mathrm{M} \Vdash_{\mathrm{w}, \mathrm{s}} \varphi$;

- $\quad M \Vdash \varphi$ iff for any world $w \in W, M \Vdash^{w} \varphi$;

Let $\Gamma$ be a set of formulas, $\alpha$ a formula and $\mathscr{F}$ a class of frames. The relation of logical consequence $\vDash$ is defined as usual: $\alpha$ is an $\mathscr{F}$-logical consequence of $\Gamma$ (in symbols: $\Gamma \vDash$ $\alpha$ iff for every $\mathscr{F}$-model $M$ such that $M \Vdash \beta$ for every $\beta \in \Gamma$, $\mathrm{M} \Vdash \alpha$. If $\alpha$ is such that $\varnothing \vDash \alpha$, we say that $\alpha$ is an $\mathscr{F}-$ tautology. Mention to $\mathscr{F}$ might me omitted in the case $\mathscr{F}$ is identical to the set of all frames.

Three tautologies are of special importance:

(NE) $\forall \mathrm{x} \square \exists \mathrm{y}(\mathrm{y}=\mathrm{x})$

(BF) $\forall \mathrm{x} \square \alpha \rightarrow \square \forall \mathrm{x} \alpha$

(CBF) $\square \forall \mathrm{x} \alpha \rightarrow \forall \mathrm{x} \square \alpha$ 
$\mathrm{NE}$ is the axiom of necessary existence. Adopting the usual definition for the existence predicate $\mathrm{E}$ ! as

$$
\mathrm{E} !(\mathrm{x})=_{\mathrm{def}} \exists \mathrm{y}(\mathrm{y}=\mathrm{x})
$$

, NE says that everything necessarily exists: $\forall \mathrm{x} \square \mathrm{E}$ !(x) (this is a consequence of the constant domain approach). $\mathrm{BF}$ is the famous Barcan formula. A better way to understand it is to look at its equivalent formulation in terms of the existential quantifier:

$$
\text { (BF) } \diamond \exists x \alpha \rightarrow \exists x \diamond \alpha
$$

It says that if it is possible that there is an object $x$ such that $\alpha$ is true, then there is an object (in the world of discourse, which might be our world) $x$ such that it is possible that $\alpha$. Finally, CBF is the equally famous converse Barcan formula. It says that if it is necessary that $\alpha$ is true for all objects $x$, then for all objects $x, \alpha$ is necessary.

As far as axiomatization of SQML is concerned, there are different paths that can be followed. I will use any standard axiomatization of FOL with identity (which includes modus ponens and some version of the rule of generalization Gen: from $\alpha$ conclude $\forall \mathrm{x} \alpha$ ) plus the following axioms:

$$
\begin{aligned}
& \text { (K) } \square(\alpha \rightarrow \beta) \rightarrow(\square \alpha \rightarrow \square \beta) \\
& \text { (BF) } \forall x \square \alpha \rightarrow \square \forall x \alpha
\end{aligned}
$$

and the rule of necessitation:

(N) from $\alpha$ conclude $\square \alpha$.

The notions of derivation and deduction $(\vdash)$ are defined in the usual way. $\mathrm{NE}$ and $\mathrm{CBF}$ are theorems in this 
axiomatization ${ }^{20}$. This axiomatics is sound and complete with respect to the set of all frames (that is to say, when $\vDash$ is constructed with $\mathscr{F}$ as the set of all frames).

If we add axiom $\mathrm{T}$

(T) $\square \alpha \rightarrow \alpha$

to this axiomatization, we obtain a version of the SQML that Hughes and Cresswell (1968, p. 141-169) call the modal lower

${ }^{20}$ Here are the derivations of $\mathrm{NE}$ and $\mathrm{CBF}$. A1-A3 are FOL axioms/theorems; $A 3$ is $\forall x(\alpha \rightarrow \beta) \rightarrow(\alpha \rightarrow \forall x \beta)$, where $x$ is not free in $\alpha$ (further FOL axioms/theorems will be referred to as A4, A5, (..).

(NE) $\vdash \forall \mathrm{x} \square \exists \mathrm{y}(\mathrm{y}=\mathrm{x})$

$1 . \exists \mathrm{y}(\mathrm{y}=\mathrm{x})$

A1

2. $\square \exists \mathrm{y}(\mathrm{y}=\mathrm{x})$

N 1

3. $\forall \mathrm{x} \square \exists \mathrm{y}(\mathrm{y}=\mathrm{x})$

Gen 2

$(\mathrm{CBF}) \vdash \square \forall \mathrm{x} \alpha \rightarrow \forall \mathrm{x} \square \alpha$

1. $\forall \mathrm{x} \alpha \rightarrow \alpha$

A2

2. $\square(\forall x \alpha \rightarrow \alpha)$

N 1

3. $\square(\forall \mathrm{x} \alpha \rightarrow \alpha) \rightarrow(\square \forall \mathrm{x} \alpha \rightarrow \square \alpha) \quad \mathrm{K}$

4. $\square \forall \mathrm{x} \alpha \rightarrow \square \alpha$ MP 3,2

5. $\forall \mathrm{x}(\square \forall \mathrm{x} \alpha \rightarrow \square \alpha)$ Gen 4

6. $\forall \mathrm{x}(\square \forall \mathrm{x} \alpha \rightarrow \square \alpha) \rightarrow(\square \forall \mathrm{x} \alpha \rightarrow \forall \mathrm{x} \square \alpha)$

7. $\square \forall \mathrm{x} \alpha \rightarrow \forall \mathrm{x} \square \alpha$ MP 5,6

Manuscrito - Rev. Int. Fil. Campinas, v. 44, n. 4, pp. 224-260, Oct.-Dec. 2021. 
predicate calculus ${ }^{21}$ which is sound and complete with respect to the set of all reflexive frames (that is to say, frames $<\mathrm{W}, \mathrm{R}>$ such that $\mathrm{R}$ is reflexive: for every $\mathrm{w} \in \mathrm{W}$, wRw). If we further add axiom $\mathrm{B}$

(B) $\alpha \rightarrow \square \vee \alpha$

, we obtain an axiomatics that is sound and complete with respect to the set of all reflexive and symmetric frames (a relation $\mathrm{R}$ is symmetric iff, for every $\mathrm{w}, \mathrm{w}^{\prime} \in \mathrm{W}$, if $w \mathrm{Rw}$ ' then w'Rw).

If in addition $\mathrm{R}$ is transitive (for every $\mathrm{w}, \mathrm{w}, \mathrm{w}$ " $\in \mathrm{W}$, if wRw' and w'Rw" then wRw") we get an equivalence frame. Despite its apparent universality, equivalence frames can have world gaps, that is to say, pairs of worlds that are not related in any way to each other. One way to avoid that is to require a frame to be universal: that every $w, w^{\prime} \in W$ be such that wRw". All universal frames are equivalence frames, but not all equivalence frames are universal frames. A weaker way to prevent world gaps is through what I call pseudouniversal frames. Let $\mathrm{F}=\left\langle\mathrm{W}, \mathrm{R}>\right.$ be a frame and $\mathrm{w}, \mathrm{w}^{\prime} \in \mathrm{W}$. There is a path from $w$ to $w^{\prime}$ (in symbols: wPw') iff (i) wRw' or (ii) there is w" $\in \mathrm{W}$ such that wPw" and w"Pw'. F is a psendo-universal frame iff, for every $\mathrm{w}, \mathrm{w}, \in \mathrm{W}, \mathrm{wPw}$ ". Pseudouniversal frames are neither reflexive, nor symmetric nor transitive. However, in a pseudo-universal frame every world is at least indirectly related to each other.

My second version of the theory of the concept of God will be represented within the version of SQML based on K, $\mathrm{BF}, \mathrm{T}$ and $\mathrm{B}$ on the proof-theoretical side, and on reflexive, symmetric and pseudo-universal frames, on the semantical

21 They do not use the expression "simplest quantified modal logic".

Manuscrito - Rev. Int. Fil. Campinas, v. 44, n. 4, pp. 224-260, Oct.-Dec. 2021. 
side $^{22}$. The reasons behind these theoretical choices will be explained in the following section.

\section{Modal Foundations of the Concept of God}

A possible world corresponds roughly to a FOL model. In the FOL approach to the concept of God we saw earlier, a FOL model corresponds to a complete theological worldview, which in turn corresponds to a specific Dconcept of God. In the SQML approach I am about to present here, a complete theological worldview and its respective D-concept of God correspond to a possible world $w$. I therefore call $w$ a theological world. Since a SQML model has a variety of theological worlds, differently from the FOL approach, this SQML approach can properly deal with PG.

Let $\mathrm{M}=<\mathrm{W}, \mathrm{R}, \mathrm{D}, \mathrm{V}>$ be a SQML model. The idea is that $\mathrm{M}$ represents the pertinent theological aspects of the social reality we live in. This, it should not represent all logically possible theological worldviews and concepts of God, but only those to which we attach some social, philosophical or religious relevance. The set of worlds $\mathrm{W}$ therefore must be a proper set of the set of all possible worlds. Thus, the use of a K-semantics.

Second, as I have pointed out, we want D-concepts of God to be attempts to characterize the one and same concept: the abstract object referred to by constant $g$. Since constant symbol $g$ is part of our logical vocabulary, there is an abstract object $\mathrm{o} \in \mathrm{D}$ that is the reference of $g$ (in symbols: $\mathrm{V}_{\mathrm{C}}(\mathrm{g})$ ). But since $\mathrm{D}$ is constant, that is to say, the same for every world $\mathrm{w} \in \mathrm{W}, o$ exists in every theological world $w$. And

22 Although this logic is sound, it cannot be shown to be complete, for as it happens with universal frames, no modal formula is valid in all and only pseudo-universal frames.

Manuscrito - Rev. Int. Fil. Campinas, v. 44, n. 4, pp. 224-260, Oct.-Dec. 2021. 
since we are using a rigid designators approach, constants in general and $g$ in particular denote the same object in all worlds.

Third, there is an extent to which a theological worldview can be said to accept another theological worldview. For example, a Lutheran worldview would accept most protestant worldviews, and perhaps even most Christian worldviews. It could even be said to accept a Jewish worldview (although not perhaps a monist Vedanta worldview, for example). Even though these worldviews do not picture God in the exact same way as the Lutheran worldview, they are such that an ideally rational Lutheran would accept that God could be like depicted by them. It is a kind of conceptual acceptance that has to do with religious tolerance. To accept a theological world $w$ does not mean to accept it, partially or as a whole, as true; instead, it means to accept that God could be like depicted by $w$.

This notion of theological-conceptual acceptance between worlds can be understood in terms of similarity: if $w$ accepts $w^{\prime}$, then from a theological viewpoint, specially from the viewpoint of the concepts of God involved, $w$ is similar to $w^{\prime}$. It is this similarity-based relation of theological acceptance that I want to capture with the accessibility relation R. wRw' will thus be read as: $w$ theologically accepts $w$. As a similarity relation, $\mathrm{R}$ is reflexive and symmetric: for every $w, w^{\prime} \in W, w R w$ and if $w R w$ ' then w'Rw. But it is neither euclidean nor transitive: it might be that wRw' and w'Rw" but not wRw", and it might be that wRw' and wRw" but not w'Rw'.

Fourth, as I have already mentioned, unlike some versions of SQML that try to address issues related to the actualism-possibilism debate (Linsky; Zalta 1994) (Menzel 2018), my formulation does not have a distinguished world meant to represent the actual world. If one of the theological worlds $w$ is chosen as the actual world, it's D-concept of God 
would naturally be taken as the actual D-concept of God. And since D-concepts are thought of as attempts to characterize the object denoted by $g$, this actual D-concept of God would be seen as the best or correct characterization of $g$, and therefore as the best or correct D-concept of God.

Although a different approach could be adopted, I want here to follow a neutral one, and at least epistemologically take all concepts of God on an equal footing. In other words, I want to endorse the following principle:

$\left(\mathrm{AA}_{\mathrm{C}}\right)$ We do not know what concept of God is the correct one.

This is what I call the conceptual agnostic assumption. There is however another, more standard agnostic assumption:

$\left(\mathrm{AA}_{\mathrm{E}}\right)$ We do not know whether GOD exists.

I call this the extensional agnostic assumption ( $\left.\mathrm{AA}_{\mathrm{E}}\right)$. In a sense, both $\left(\mathrm{AA}_{\mathrm{C}}\right)$ and $\left(\mathrm{AA}_{\mathrm{E}}\right)$ are general desiderata of a genuine pluralistic approach. While $\left(\mathrm{AA}_{\mathrm{C}}\right)$ takes all concepts of God on an equal footing, $\left(\mathrm{AA}_{\mathrm{C}}\right)$ allows for atheistic and agnostic worldviews.

Here one might object that $\left(\mathrm{AA}_{\mathrm{E}}\right)$ cannot be satisfied in my modal approach. It seems that any theological worldview includes the assumption that GOD exists. A Christian worldview seems to include the assumption that there is an entity that falls under the Christian concept of God, for example. As I have said, a theological world $w$ is a complete theological worldview. Therefore, the Christian theological world $w$ obviously includes the assumption that GOD exists. In other words, there is a nonabstract object $o \in \mathrm{D}$ such that $o$ is an instance of $g$ (in symbols: $<_{\mathrm{O}}, \mathrm{V}_{\mathrm{C}}(\mathrm{g})>\in \mathrm{V}_{\mathrm{P}}(\mathrm{I}, \mathrm{w})$ ). Since this holds for every $w \in W$, a model $M$ is unable to satisfy $\left(\mathrm{AA} \mathrm{E}_{\mathrm{E}}\right.$. 
In order to address this, I have to elaborate more on the notions of theological worldview and theological world. First of all, not every theological worldview is theist. A theological worldview is a worldview that includes a view on God. As such, it might be either positive, negative or neutral regarding GOD's existence. This implies that there are atheist and agnostic theological worldviews, as well as atheist and agnostic theological worlds. Notice that even an atheist or agnostic worldview includes a specific concept of God. While an atheistic worldview denies that there is an object which falls under its specific concept of God, an agnostic worldview acknowledges that we do not know that there is an object which falls under its concept of God.

Second, following here what is perhaps the standard in philosophical modal logic, I am attributing an ideal degree of rationality to the notions of theological world and theological worldview, or to be more precise, to the agent that holds a theological worldview. Although an ideally rational theistic agent naturally believes in GOD's existence, it (the agent) will include GOD in the category of existing things only if she has strong evidence supporting this. If she does not, then there will be no nonabstract object instantiating her concept of God. Therefore, it is possible for an ideally rational theist agent that, while believing that GOD exists, she does not include GOD's existence in her worldview. Thus, there might be a theist theological world $w$ in which there is no nonabstract object $\mathrm{o} \in \mathrm{D}$ such that $<_{\mathrm{O}}, \mathrm{V}_{\mathrm{C}}(\mathrm{g})>\in \mathrm{V}_{\mathrm{P}}(\mathrm{I}, \mathrm{w})$.

From another perspective, I could reply to this by noticing that a FOL set of formulas $\Delta$ that is such that $\Delta \vdash$ $\delta$, where $\delta$ is a D-concept of God, might be such that no formula of the form $\mathrm{I}(\mathrm{x}, \mathrm{g})$ is a theorem of $\Delta(\Delta \vdash \mathrm{I}(\mathrm{x}, \mathrm{g}))$. Therefore, both kinds of models $\mathrm{M}$ - those in which GOD exists and those in which GOD does not exist—satisfy $\Delta$. 


\section{A SQML Theory of the Concept of God}

In Sections 2 and 3, several notions were defined, culminating at what I called the $\Lambda$-FOL theory of the concept of God applied to $\Gamma$ ( $\Gamma$ is a theological background and $\Lambda$ a SPfree set of FOL formulas containing only $\mathrm{D}$-concepts of God). I will here follow the same approach, using all the notions defined in these sections. Just some few adjustments will have to be made.

All postulates introduced in Section 2 (C1-C5 and M1M5) remain the same, but now instantiated within SQML language. In order to account for the modal subtilities of this new account, I need to introduce only two new postulates:

$$
\begin{aligned}
& \text { (C6) } \forall \mathrm{x}(\mathrm{C}(\mathrm{x}) \rightarrow \square \mathrm{C}(\mathrm{x})) \\
& \text { (C7) } \forall \mathrm{x}(\diamond \mathrm{I}(\mathrm{x}, \mathrm{g}) \rightarrow \mathrm{I}(\mathrm{x}, \mathrm{g}))
\end{aligned}
$$

C6 states that a concept is necessarily a concept. A consequence of that is that concepts are necessarily abstract:

$$
\text { (T1) } \forall \mathrm{x}(\mathrm{C}(\mathrm{x}) \rightarrow \square \mathrm{A}(\mathrm{x}))^{23}
$$

${ }^{23}$ Here is the derivation (R1 and $\mathrm{R} 2$ are FOL derived rules $\forall \mathrm{x} \alpha(\mathrm{x}) \vdash \alpha[\mathrm{x} / \mathrm{t}]$ and $\alpha \rightarrow \beta, \beta \rightarrow \varphi \vdash \alpha \rightarrow \varphi$, respectively):

1. $\forall \mathrm{x}(\mathrm{C}(\mathrm{x}) \rightarrow \square \mathrm{C}(\mathrm{x}))$

2. $\mathrm{C}(\mathrm{x}) \rightarrow \square \mathrm{C}(\mathrm{x}) \quad$ R1 1

3. $\forall \mathrm{x}(\mathrm{C}(\mathrm{x}) \rightarrow \mathrm{A}(\mathrm{x}))$

4. $\mathrm{C}(\mathrm{x}) \rightarrow \mathrm{A}(\mathrm{x}) \quad$ R1 3

5. $\square(\mathrm{C}(\mathrm{x}) \rightarrow \mathrm{A}(\mathrm{x})) \quad \mathrm{N} 4$ 
Since this restriction applies only to concepts, abstract objects that are not concepts might be said to be abstract only contingently. The same holds for nonabstract objects and concrete objects (as I explained earlier, concreteness is a subcategory of nonabstractness) ${ }^{24}$.

C7 states that if it is possible that $x$ is an instance of the concept of God, then $x$ is an instance of the concept of God. In other words, if for example $o$ is an instance of $g$ at world $w$, then $o$ is an instance of $g$ also at the world of reference $w$. This entails that if it is possible that there is an instance of God, then there is an instance of God;

(T2) $\diamond \exists x(I(x, g)) \rightarrow \exists x(I(x, g))^{25}$

$$
\begin{array}{ll}
\text { 6. } \square(\mathrm{C}(\mathrm{x}) \rightarrow \mathrm{A}(\mathrm{x})) \rightarrow(\square \mathrm{C}(\mathrm{x}) \rightarrow \square \mathrm{A}(\mathrm{x})) & \mathrm{K} \\
\text { 7. } \square \mathrm{C}(\mathrm{x}) \rightarrow \square \mathrm{A}(\mathrm{x}) & \text { MP 5,6 } \\
\text { 8.C (x) } \rightarrow \square \mathrm{A}(\mathrm{x}) & \text { R2 2,7 }
\end{array}
$$

${ }^{24}$ In special, this implies that there might an object $o$ that in world $w$ is abstract, but in world $w^{\prime}$ is concrete. This allows us to respond to several actualist objections that are usually raised against SQML. See (Linsky; Zalta 1994).

25 Here is the derivation (R3 is FOL derived rules $\alpha[\mathrm{x} / \mathrm{c}] \rightarrow \beta \vdash \exists \mathrm{x} \alpha \rightarrow \beta$, where $\mathrm{c}$ is a constant that does not appear either in $\alpha$ or $\beta$; it can be obtained from rule El (Enderton 1972, p. 117) along with theorem of deduction:
$1 . \diamond \exists \mathrm{x}(\mathrm{I}(\mathrm{x}, \mathrm{g})) \rightarrow \exists \mathrm{x} \diamond \mathrm{I}(\mathrm{x}, \mathrm{g})$
$\mathrm{BF}$
2. $\forall \mathrm{x}(\diamond \mathrm{I}(\mathrm{x}, \mathrm{g}) \rightarrow \mathrm{I}(\mathrm{x}, \mathrm{g}))$
C6
3. $\diamond \mathrm{I}(\mathrm{a}, \mathrm{g}) \rightarrow \mathrm{I}(\mathrm{a}, \mathrm{g})$
R1 2
4.I $(\mathrm{a}, \mathrm{g}) \rightarrow \exists \mathrm{x}(\mathrm{I}(\mathrm{x}, \mathrm{g}))$
A4 
It also entails that if $x$ is an instance of God, necessarily it is an instance of God:

$$
\text { (T3) } \forall \mathrm{x}(\mathrm{I}(\mathrm{x}, \mathrm{g}) \rightarrow \square \mathrm{I}(\mathrm{x}, \mathrm{g}))^{26}
$$

Other consequence of $\mathrm{C} 7$ is that if $x$ is an instance of God, then it is necessarily a nonabstract object:

(T4) $\forall \mathrm{x}(\mathrm{I}(\mathrm{x}, \mathrm{g}) \rightarrow \square \neg \mathrm{A}(\mathrm{x}))^{27}$

\begin{tabular}{|c|c|}
\hline 5. $\mathrm{I}(\mathrm{a}, \mathrm{g}) \rightarrow \exists \mathrm{x}(\mathrm{I}(\mathrm{x}, \mathrm{g}))$ & R2 3,4 \\
\hline 6. $\exists \mathrm{x} \oslash \mathrm{I}(\mathrm{x}, \mathrm{g}) \rightarrow \exists \mathrm{x}(\mathrm{I}(\mathrm{x}, \mathrm{g}))$ & R3 5 \\
\hline 7. $\diamond \exists \mathrm{x}(\mathrm{I}(\mathrm{x}, \mathrm{g})) \rightarrow \exists \mathrm{x}(\mathrm{I}(\mathrm{x}, \mathrm{g}))$ & R2 1,6 \\
\hline \multicolumn{2}{|l|}{${ }^{26}$ Here is the derivation: } \\
\hline 1. $\diamond \exists \mathrm{x}(\mathrm{I}(\mathrm{x}, \mathrm{g})) \rightarrow \exists \mathrm{x} \diamond \mathrm{I}(\mathrm{x}, \mathrm{g})$ & $\mathrm{BF}$ \\
\hline 2. $\forall \mathrm{x}(\diamond \mathrm{I}(\mathrm{x}, \mathrm{g}) \rightarrow \mathrm{I}(\mathrm{x}, \mathrm{g}))$ & C6 \\
\hline $3 . \diamond \mathrm{I}(\mathrm{a}, \mathrm{g}) \rightarrow \mathrm{I}(\mathrm{a}, \mathrm{g})$ & $\mathrm{R} 12$ \\
\hline 4.I $(\mathrm{a}, \mathrm{g}) \rightarrow \exists \mathrm{x}(\mathrm{I}(\mathrm{x}, \mathrm{g}))$ & A4 \\
\hline $5 . \diamond \mathrm{I}(\mathrm{a}, \mathrm{g}) \rightarrow \exists \mathrm{x}(\mathrm{I}(\mathrm{x}, \mathrm{g}))$ & R2 3,4 \\
\hline 6. $\exists \mathrm{x} \oslash \mathrm{I}(\mathrm{x}, \mathrm{g}) \rightarrow \exists \mathrm{x}(\mathrm{I}(\mathrm{x}, \mathrm{g}))$ & R3 5 \\
\hline 7. $\diamond \exists \mathrm{x}(\mathrm{I}(\mathrm{x}, \mathrm{g})) \rightarrow \exists \mathrm{x}(\mathrm{I}(\mathrm{x}, \mathrm{g}))$ & R2 1,6 \\
\hline \multicolumn{2}{|l|}{${ }^{27}$ Here is the derivation: } \\
\hline 1. $\forall \mathrm{x}(\mathrm{I}(\mathrm{x}, \mathrm{g}) \rightarrow \neg \mathrm{A}(\mathrm{x}))$ & C3 \\
\hline 2.I $(\mathrm{x}, \mathrm{g}) \rightarrow \neg \mathrm{A}(\mathrm{x})$ & R1 1 \\
\hline 3. $\square(\mathrm{I}(\mathrm{x}, \mathrm{g}) \rightarrow \neg \mathrm{A}(\mathrm{x}))$ & N 2 \\
\hline
\end{tabular}


There still an important consequence of $\mathrm{C} 7$ that comes along when we take C5 into account. C5 guarantees an intraworld monotheism, as we might call it: if $x$ and $y$ are both instances of God, then $x$ is identical to $y$. But C7 guarantees that if $x$ is an instance of God in a world $w^{\prime}$, then it is also an instance of God in the world of reference $w$. We therefore have a transworld monotheism according to which if $x$ is an instance of God in some world $w^{\prime}$, then if $y$ is an instance of God in the world of reference $w$, then $x$ is identical to $y$ :

$$
\text { (T5) } \forall \mathrm{x} \forall \mathrm{y}(\diamond \mathrm{I}(\mathrm{x}, \mathrm{g}) \rightarrow(\mathrm{I}(\mathrm{y}, \mathrm{g}) \rightarrow \mathrm{x}=\mathrm{y}))^{28}
$$

\begin{tabular}{|c|c|}
\hline 4. $\square(\mathrm{I}(\mathrm{x}, \mathrm{g}) \rightarrow \neg \mathrm{A}(\mathrm{x})) \rightarrow(\square \mathrm{I}(\mathrm{x}, \mathrm{g}) \rightarrow \square \neg \mathrm{A}(\mathrm{x}))$ & $\mathrm{K}$ \\
\hline 5. $\square \mathrm{I}(\mathrm{x}, \mathrm{g}) \rightarrow \square \neg \mathrm{A}(\mathrm{x})$ & $\mathrm{MP} 3,4$ \\
\hline 6. $\forall \mathrm{x}(\mathrm{I}(\mathrm{x}, \mathrm{g}) \rightarrow \square \mathrm{I}(\mathrm{x}, \mathrm{g}))$ & $\mathrm{T} 3$ \\
\hline 7.I $(\mathrm{x}, \mathrm{g}) \rightarrow \square \mathrm{I}(\mathrm{x}, \mathrm{g})$ & R1 6 \\
\hline 8.I $(\mathrm{x}, \mathrm{g}) \rightarrow \square \neg \mathrm{A}(\mathrm{x})$ & R2 7,5 \\
\hline 9. $\forall \mathrm{x}(\mathrm{I}(\mathrm{x}, \mathrm{g}) \rightarrow \square \neg \mathrm{A}(\mathrm{x}))$ & Gen 8 \\
\hline \multicolumn{2}{|l|}{${ }^{28}$ Here is the derivation: } \\
\hline 1. $\forall \mathrm{x} \forall \mathrm{y}(\mathrm{I}(\mathrm{x}, \mathrm{g}) \rightarrow(\mathrm{I}(\mathrm{y}, \mathrm{g}) \rightarrow \mathrm{x}=\mathrm{y}))$ & $\mathrm{C} 4$ \\
\hline 2.I $(\mathrm{x}, \mathrm{g}) \rightarrow(\mathrm{I}(\mathrm{y}, \mathrm{g}) \rightarrow \mathrm{x}=\mathrm{y})$ & $\mathrm{R} 11(2 \mathrm{x})$ \\
\hline 3. $\forall \mathrm{x}(\diamond \mathrm{I}(\mathrm{x}, \mathrm{g}) \rightarrow \mathrm{I}(\mathrm{x}, \mathrm{g}))$ & C6 \\
\hline $4 . \diamond \mathrm{I}(\mathrm{x}, \mathrm{g}) \rightarrow \mathrm{I}(\mathrm{x}, \mathrm{g})$ & R1 3 \\
\hline $5 . \diamond \mathrm{I}(\mathrm{x}, \mathrm{g}) \rightarrow(\mathrm{I}(\mathrm{y}, \mathrm{g}) \rightarrow \mathrm{x}=\mathrm{y})$ & R2 4,2 \\
\hline 6. $\forall \mathrm{x} \forall \mathrm{y}(\diamond \mathrm{I}(\mathrm{x}, \mathrm{g}) \rightarrow(\mathrm{I}(\mathrm{y}, \mathrm{g}) \rightarrow \mathrm{x}=\mathrm{y}))$ & Gen $5(2 x)$ \\
\hline
\end{tabular}

Manuscrito - Rev. Int. Fil. Campinas, v. 44, n. 4, pp. 224-260, Oct.-Dec. 2021. 
But this works only if there are no world gaps, that is to say, worlds that in no way are related to each other. Formally a world gap could be defined as follows. Let $\mathrm{F}=$ $<\mathrm{W}, \mathrm{R}>$ be a frame. $\mathrm{F}$ has world gaps iff there are $\mathrm{w}, \mathrm{w}^{\prime} \in \mathrm{W}$ such that there is no path from $w$ to $w$ " (in symbols: wPw"). If $F$ has world gaps, then it might be that, for w,w' $\in \mathbb{W}, \mathrm{M}$ $\Vdash_{w, s} I(x, g)$ and $M \Vdash_{w^{\prime}, s} I(x, g)$, which opens the door for the possibility that $\mathrm{M} \Vdash_{w^{\prime}, \mathrm{s}} \mathrm{I}(\mathrm{y}, \mathrm{g})$ with $\mathrm{M} \Vdash_{w^{\prime}, \mathrm{s}} \mathrm{x}=\mathrm{y}$, which violates both AM and EAM. So, the need of having only pseudouniversal frames.

A final and trivial consequence of our new framework is that $g$ is necessarily a concept:

$$
\text { (T6) } \square \mathrm{C}(\mathrm{g})^{29}
$$

In order to introduce the modal version of $\Gamma_{\Lambda}$ we just need now to slightly reformulate the notion of theological background and introduce the notion of a $\diamond$-version of a set of formulas. A theological background $\Gamma$ is a SP-free set of SQML formulas representing known facts about the world as well as formulas setting the relations between the pertinent (non-special) predicate symbols. Let $\Delta$ be a set of formulas of SQML. The $\diamond$-version of $\Delta$ (in symbols: $\Delta^{\natural}$ ) is defined as follows: (i) if $\alpha \in \Delta$, then $\diamond \alpha \in \Delta^{\diamond}$; (ii) nothing else belongs to $\Delta^{\diamond}$.

${ }^{29}$ Here is the derivation:

1.C $(\mathrm{g})$

2. $\square \mathrm{C}(\mathrm{g})$ 
Let $\Gamma$ be a theological background and $\Lambda$ a SP-free set of FOL formulas containing only D-concepts of God. Let also $\Pi$ be the set of all $\delta$-instances of M5, for all $\delta \in \Lambda$. The $\Lambda$ SQML theory of the concept of God applied to $\Gamma$ is the set of SQML formulas $\Gamma_{\Lambda}$ composed by (an only by) $\Gamma, \Lambda^{\diamond}, \Pi^{\diamond}$ $\left(\Gamma \cup \Lambda^{\diamond} \cup \Pi^{\triangleright} \subset \Gamma_{\Lambda}\right), \mathrm{C} 1-\mathrm{C} 7, \mathrm{M} 1-\mathrm{M} 3$ and all instances of M4.

For the sake of simplicity, I still require that the Dconcepts of God of $\Lambda$ be FOL formulas. $\Gamma$, however, might contain modal formulas. Besides the use of a different logical framework (SQML) and the additional postulates, the main difference between this version of my logical theory of the concept of God and the previous one relates to the way I take the members of $\Lambda$.

As I said earlier, the idea of using a modal approach is that each theological world corresponds to a D-concept of God. In this way we are able to accommodate contradictory D-concepts of God: since D-concepts of God relate to different possible worlds, having contradictory D-concepts does not trivialize the theory. That is why I take $\Lambda^{\diamond}$ and not $\Lambda$. It is also because of that that the $\delta$-instances of M5 have also to be relativized in terms of possible worlds.

Consider the D-concepts of God $\mathrm{P}_{2}$ and $\mathrm{P}_{3}$ :

$$
\begin{aligned}
& \left(\mathrm{P}_{2}\right) 3 \mathrm{O}(\mathrm{g}) \wedge \mathrm{F}(\mathrm{g}) \\
& \left(\mathrm{P}_{3}\right) 3 \mathrm{O}(\mathrm{g}) \wedge \mathrm{T}(\mathrm{g})
\end{aligned}
$$

As we saw, supposing that $\Gamma$ is such that $\Gamma \vdash \mathrm{P}_{7}$

$$
\text { ( } \left.\mathrm{P}_{7}\right) \forall \mathrm{x}(\mathrm{T}(\mathrm{x}) \rightarrow \neg \mathrm{F}(\mathrm{x}))
$$

, $\mathrm{P}_{2}$ and $\mathrm{P}_{3}$ are mutually $\Gamma$-contradictory. Suppose now that $\mathrm{P}_{2}, \mathrm{P}_{3} \in \Lambda$. $\mathrm{P}_{2}$ and $\mathrm{P}_{3}$ do not belong to $\Gamma_{\Lambda}$. Instead, their $\diamond$ versions do: 


$$
\begin{aligned}
& \left(\mathrm{P}_{12}\right) \diamond(3 \mathrm{O}(\mathrm{g}) \wedge \mathrm{F}(\mathrm{g})) \\
& \left(\mathrm{P}_{13}\right) \diamond(3 \mathrm{O}(\mathrm{g}) \wedge \mathrm{T}(\mathrm{g}))
\end{aligned}
$$

Similarly, it is not their corresponding instances of M5

$$
\begin{aligned}
& \left(\mathrm{P}_{10}\right) \forall \mathrm{x}((3 \mathrm{O}(\mathrm{g}) \wedge \mathrm{F}(\mathrm{g}) \leftrightarrow 3 \mathrm{O}(\mathrm{x}) \wedge \mathrm{F}(\mathrm{x})) \rightarrow \mathrm{x} \cong \mathrm{g}) \\
& \left(\mathrm{P}_{14}\right) \forall \mathrm{x}((3 \mathrm{O}(\mathrm{g}) \wedge \mathrm{T}(\mathrm{g}) \leftrightarrow 3 \mathrm{O}(\mathrm{x}) \wedge \mathrm{T}(\mathrm{x})) \rightarrow \mathrm{x} \cong \mathrm{g})
\end{aligned}
$$

that belong to $\Gamma_{\Lambda}$, but the $\diamond$-versions of them:

$$
\begin{aligned}
& \left(\mathrm{P}_{15}\right) \diamond \forall \mathrm{x}((3 \mathrm{O}(\mathrm{g}) \wedge \mathrm{F}(\mathrm{g}) \leftrightarrow 3 \mathrm{O}(\mathrm{x}) \wedge \mathrm{F}(\mathrm{x})) \rightarrow \mathrm{x} \cong \mathrm{g}) \\
& \left(\mathrm{P}_{16}\right) \diamond \forall \mathrm{x}((3 \mathrm{O}(\mathrm{g}) \wedge \mathrm{T}(\mathrm{g}) \leftrightarrow 3 \mathrm{O}(\mathrm{x}) \wedge \mathrm{T}(\mathrm{x})) \rightarrow \mathrm{x} \cong \mathrm{g})
\end{aligned}
$$

See that in the same way that there might be contradictory D-concepts of God, that is to say, conflicting descriptions of $g$, there also might be conflicting descriptions of an eventual object that falls under $g$. Let me explain this from a semantical viewpoint. Let $\mathrm{M}=<\mathrm{W}, \mathrm{R}, \mathrm{D}, \mathrm{V}>$ be a model such that $\mathrm{M} \Vdash \alpha$ for all $\alpha \in \Gamma_{\Lambda}$. Let also $\mathrm{w}, \mathrm{w} \in \mathrm{W}$ be such that $w R w^{\prime}, M \Vdash_{w} P_{2}, M \Vdash_{w} P_{10}, M \Vdash_{w} P_{3}$ and $M \Vdash_{w} P_{14}$. Suppose now that $\mathrm{M} \Vdash_{\mathrm{w}} 3 \mathrm{O}(\mathrm{a}) \wedge \mathrm{F}(\mathrm{a})$ and $\mathrm{M} \Vdash_{\mathrm{w}^{\prime}} 3 \mathrm{O}(\mathrm{b}) \wedge \mathrm{T}(\mathrm{b})$. Then we will have that $\mathrm{M} \Vdash_{\mathrm{w}} \mathrm{I}(\mathrm{a}, \mathrm{g})$ and $\mathrm{M} \Vdash_{\mathrm{w}^{\prime}} \mathrm{I}(\mathrm{b}, \mathrm{g})$. But through $\mathrm{C} 7$ we have that $\mathrm{M} \Vdash_{w} \mathrm{I}(\mathrm{b}, \mathrm{g})$ and $\mathrm{M} \Vdash_{w^{\prime}} \mathrm{I}(\mathrm{a}, \mathrm{g})$, and through $\mathrm{C} 5$ that $\mathrm{M} \Vdash_{\mathrm{w}} \mathrm{a}=\mathrm{b}$ and $\mathrm{M} \Vdash_{\mathrm{w}}, \mathrm{a}=\mathrm{b}$. But since $\mathrm{P}_{7}$ is valid in both $\mathrm{w}$ and $\mathrm{w}$ ', we have that $\mathrm{M} \Vdash_{\mathrm{w}} \mathrm{F}(\mathrm{a})$ and $\mathrm{M} \Vdash_{\mathrm{w}} \neg \mathrm{F}(\mathrm{b})$, and $\mathrm{M}$ $\Vdash_{w}{ }^{\prime} T(b)$ and $M \Vdash_{w} \neg T(a)$. Thus, GOD - the object that falls under the concept of God-is described in contradictory ways in $w$ and $w^{\prime}$. This is a further evidence that my framework properly deals with the plurality of views on GOD.

But if $\Lambda$ is such that there are no contradictory $D$ concepts of God, it might happen that there is a core D- 
concept of God, which is the description of God that is shared by all $\mathrm{D}$-concepts of God. If, for example, $\Lambda=$ $\left\{\mathrm{P}_{1}, \mathrm{P}_{2}, \mathrm{P}_{3}, \mathrm{P}_{4}, \mathrm{P}_{5}\right\}$ and neither $\mathrm{P}_{6}$ nor $\mathrm{P}_{7}$ not $\mathrm{P}_{8}$ belong to or can be deduced from $\Gamma$. Then $\mathrm{P}_{1}$ will be the core $\mathrm{D}$-concept of God. We would thus have that $\Gamma_{\Lambda} \vDash \square \mathrm{P}_{1}$.

\section{Conclusion}

In this paper I tried to answer four basic questions: (1) How the concept of God is to be represented? (2) Are there any logical principles governing it? (3) If so, what kind of logic lies behind them? (4) Can there be a logic of the concept of God? These questions were addressed through the introduction of a formal-logical account to the concept of God. Within this approach, their answers can be summarized as follows:

(1) The concept of God is to be represented in two different ways. The actual concept of God, so to speak, the one that satisfies SA, is to be represented as a constant $g$ denotating an abstract object. This concept of God (that is, a specific abstract object) can be descriptively represented through a FOL formula specifying the attributes possessed by it. By representing these so-called D-concept of God with the help of the modal operator $\diamond$ we were also able to satisfy PG.

(2) There are several principles governing the concept of God, especially principles relating abstractness, concepthood, instantiation and modality. C1-C7, M1-M5 and T1-T6 are examples of such principles. 
(3) The logic behind these principles is SQML based on $\mathrm{K}, \mathrm{BF}, \mathrm{T}$ and $\mathrm{B}$ on the prooftheoretical side, and on reflexive, symmetric and pseudo-universal frames, on the semantical side.

(4) Yes, there can be a logic of the concept of God. The formalization herein presented can be seen as an exemplar of such a logic.

It should be emphasized that these answers are parametrized by my formalization and the theoretical choices that guided it. Of course, if other logical framework were used and other theoretical decisions were made, questions (1)-(3) would be answered differently. However, if one accepts the methodological criterion that I have been following (of using the simplest existing logical formalism), then these answers go from mere possible answers to quite defensible answers to (1)-(3).

\section{References}

Branson, B. (2019) "No New Solutions to the Logical Problem of the Trinity". Journal of Applied Logics 6: 1051-1092.

Enderton, H. (1972) A Mathematical Introduction to Logic. New York: Academic Press.

Esposito, J. (1998). Islam: the Straight Path. New York: Oxford University Press.

Foltz, B. (ed.) (2019) Medieval Philosophy: A Multicultural Reader. New York: Bloomsbury Academic.

Gödel, K (1995) “Texts relating to the ontological proof”. In: Kurt Gödel, Collected Works, ed. S. Feferman et al., vol. 3, Oxford: Oxford University Press, pp. 429-437. 
Hernández-Ortiz, H.; Cantero-Flores, V. (2019) “A Logical Solution to the Paradox of the Stone". Journal of Applied Logics 6: 1037-1050.

Hughes G. E.; Cresswell M. J. (1968) An Introduction to Modal Logic. London: Methuen and Co. Ltd.

Krajewski, S; Silvestre, R. (2019) "Logic and the Concept of God”. Journal of Applied Logics 6: 999-1005.

Laurence, S. \& Margolis, E. (1999). "Concepts and Cognitive Science". In: E. Margolis \& S. Laurence (eds.), Concepts: Core Readings, Cambridge, MA: MIT Press, pp. 3-81.

Lewis, D. (1986) On the Plurality of Worlds. Oxford: Basil Blackwell.

Linsky, B.; Zalta, E. (1994) "In Defense of the Simplest Quantified Modal Logic.” In: J. Tomberlin (ed.), Philosophical Perspectives 8: Logic and Language, Atascadero: Ridgeview, pp. 431-458.

Margolis, E.; Laurence, S. (2007) "The Ontology of Concepts-Abstract Objects or Mental Representations?" Noûs 41: 561-593.

Menzel, C. (2018) “Actualism”. In: Edward N. Zalta (ed.), The Stanford Encyclopedia of Philosophy (Summer 2018 Edition), URL $<$ https://plato.stanford.edu/archives/sum2018/entr ies/actualism/ $>$.

Molto, D. (2017) "The Logical Problem of the Trinity and the Strong Theory of Relative Identity". Sophia: International Journal of Philosophy and Traditions 56: 227245.

Murphy, G. (2002). The Big Book of Concepts. Cambridge, MA: MIT Press. 
Resnick, H. (1995). "Kṛșna in the Bhagavad-gitā: A Beginning Ontology from the Gaudīya Perspective". Journal of V aishnava Studies 3: 5-32.

Rosen, G. (2020) “Abstract Objects". In: Edward N. Zalta (ed.), The Stanford Encyclopedia of Philosophy (Spring 2020 Edition), URL = $<$ https://plato.stanford.edu/archives/spr2020/entri es/abstract-objects/>.

Schurz, G. (2002) “Alethic Modal Logics and Semantics." In: D. Jacquette (ed.), A Companion to Philosophical Logic, Oxford: Blackwell Publishing, pp. 442-477.

Swinburne, R. (2016) The Coherence of Theism, second edition. New York: Oxford University Press.

Tuggy, D. (2006). “Trinity". In Edward N. Zalta (ed.), The Stanford Encyclopedia of Philosophy (Winter 2016 Edition), URL = $<$ https://plato.stanford.edu/archives/win2016/entri es/trinity/ $>$.

Zalta, E. (2000) “A (Leibnizian) Theory of Concepts.” Logical Analysis and History of Philosophy 3:137-183.

$(\infty)$ EY 